\title{
Survival pattern and cause of death in patients with multiple sclerosis: results from an epidemiological survey in north east Scotland
}

\author{
JAYANT G PHADKE \\ From the Department of Neurology, Aberdeen Royal Infirmary, Aberdeen, UK
}

SUMMARY The mean survival period in a series of 216 multiple sclerosis deaths, which formed part of a large prevalence sample observed in the Grampian region of Scotland, was 24.5 years, with an insignificant difference between females ( 25.7 years) and males (23.5 years). A third of the patients survived for over 30 years after onset. The age at death ranged between $25-80$ years, with majority of the deaths occurring in the seventh decade (37\%). On comparing life expectancy with the Scottish general population using life tables, only a slight reduction in the short-term (less than 10 years from onset) survival was noted in all age groups, with the exception of those with onset over the age of 50 years. The long-term life expectancy was however markedly reduced in all age groups compared with the controls. The survival period could be accurately predicted from the degree of disability at a point in time, and could be correlated with a number of clinical features, the most important of which was the age at onset. Eighty five per cent of those with onset of multiple sclerosis over the age of 50 years died within 20 years. Patients with a cerebellar disturbance at onset survived the shortest, and those with a brainstem lesion or retrobulbar neuritis the longest; those with a pyramidal dysfunction had an intermediate prognosis. Other parameters which could be correlated with the survival were: the timing and frequency of occurrence of psychiatric and urinary symptoms, interval between onset and first relapse and the course of the disease. As expected, most patients ( $89 \%)$ were significantly disabled (unable to walk) prior to death, only a minority, however, had become so within 10 years of the onset $(10 \%)$. Sixty two per cent of the patients died of complications of multiple sclerosis. No unusual excess of any disease was noted amongst other causes. As expected, the majority of patients $(55 \%)$ had bronchopneumonia as the terminal event, $11 \%$ had septicaemia, $15 \%$ had myocardial infarction and $4 \%$ had documented pulmonary embolism. This is the largest series of its kind where prognosis, judged by survival period, has been assessed amongst all multiple sclerosis patients derived from a prevalence sample and observed till death.

The period of survival after onset of multiple sclerosis has been reported in several previous studies. ${ }^{1-18}$ Only in some, was this based on a prospective analysis. ${ }^{10-16}$ Although some of these series were derived from a prevalence source ${ }^{1012-16}$ only in

Financial support for the study was given by the Scottish Hospital Endowment Research Trust.

Address for reprint requests: X976 Dr JG Phadke, Riyadh Military Hospital, PO Box 7897, Riyadh, 11159, Kingdom of Saudi Arabia.

Received 4 March 1986 and in revised form 4 June 1986. Accepted 6 June 1986 one $^{14}$ was a sufficiently large number of patients involved. Hence there is considerable uncertainty regarding the mean life expectancy following onset of multiple sclerosis. ${ }^{19}$

Only in a few studies has life expectancy of multiple sclerosis patients been compared with that of an age matched general population ${ }^{13-152021}$ and all except one $^{14}$ are from North America. In only one of these was a statistically estimated life expectancy used as a measure of the disease severity. ${ }^{20}$

The degree of disability at a point in time has been used before 121620 as a basis for predicting the survival period. Only in two of these reports ${ }^{12}{ }^{16}$ was the 
information based on a sample derived from a prevalence source, and only the Danish study ${ }^{12}$ encompassed a sufficiently large patient sample.

A number of clinical features, particularly those at onset of the disease have been shown to influence the survival period; ${ }^{61122}$ of these only one series, however, was derived from a prevalence source. ${ }^{22}$

Except in the series from Israel ${ }^{23}$ in most others where the cause of death in multiple sclerosis patients was analysed, a degree of selection was involved.682123-25 Some have specifically attempted to assess the frequency of malignant diseases amongst multiple sclerosis patients ${ }^{91325-27}$ and all except one ${ }^{26}$ found no undue excess: in the series of Zimmermann and Netsky ${ }^{26}$ no comparison with a control population was made.

In the north east of Scotland, a large sample of multiple sclerosis patients (1055) has been closely observed for over a decade as part of an ongoing epidemiological investigation. ${ }^{28-30}$ In this sample 216 deaths occurred between 1970-80; these represented all multiple sclerosis deaths in the region during that period. An attempt to answer a number of unsettled questions in the literature has been made. The period of survival for this unselected group was analysed and compared with age matched general population. Factors influencing the period of survival were analysed as well, and the causes of death were evaluated in detail.

\section{Method}

The Grampian region of Scotland was demarcated as a separate region in 1974 (fig 1). Three epidemiological surveys for multiple sclerosis have been carried out there since $1970 .^{28-30} \mathrm{~A}$ register for all multiple sclerosis patients was set up after the 1970 survey. All patients identified between 1970 and 1981 were periodically "flagged" with the central registrar office in Edinburgh. This facilitated automatic retrieval of death certificates of all multiple sclerosis patients. Between 1970 and 1980 there were 216 deaths. Almost all these patients had been seen on a number of occasions by a neurologist. The case notes of all these 216 deaths were re-analysed, and a number of details were recorded on a mainframe computer.

Factors such as sex, age at onset, initial symptoms, frequency and timing of occurrence of significant psychiatric and urinary symptoms and course of the disease were correlated with the length of survival calculated from the year of the first symptom to the year of death.

The age at onset was known in the case of 200 , and age at death for all the 216 patients. The initial symptoms were grouped into:

(a) Cerebral disturbance: fits, hemiplegia with upper motor neuron VIIth nerve lesion, dysphasia, psychoses, etc.

(b) Retrobulbar neuritis: unilateral or bilateral.

(c) Brainstem disturbance: hemiplegia with cranial nerve

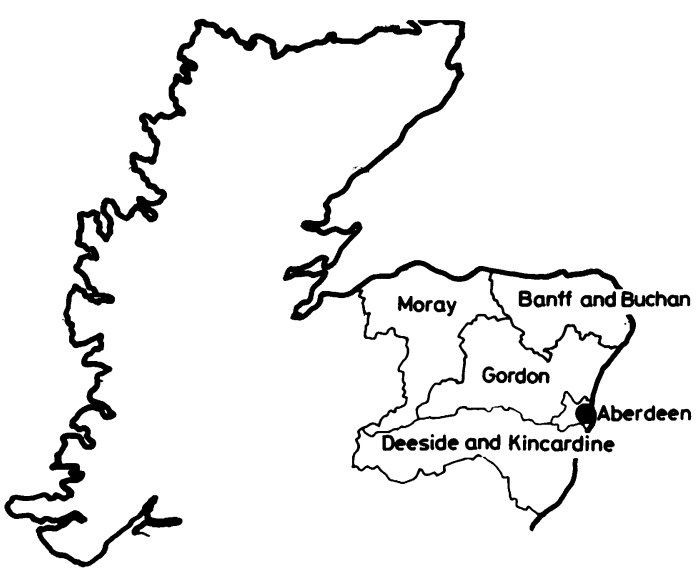

Fig 1 Map of the Grampian region of Scotland.

lesions such as the VIth or internuclear ophthalmoplegia or vertigo, etc.

(d) Pyramidal disturbance: symptoms in the limbs due to cortico-spinal tract lesions.

(e) Sensory disturbance: involving any sensory modalities over the trunk and/or extremities.

(f) Urinary disturbance.

(g) Cerebellar disturbance: incoordination of the limbs, $\underset{ }{\sigma}$ intention tremor, etc.

Information about the interval between onset and first relapse was obtained from the regularly updated index cards. For those with onset of the disease prior to arrival in the region such information was collected during a personal interview, accepting the limitations of recall on the patients' part.

The course of the disease was analysed from periodically updated index cards, case notes, and from information sent by the region's general practitioners in response to questionnaires. Four categories were defined:

(1) Remittent: if the disease was in complete remission without any resultant disability at the time of death.

(2) Relapsing cumulative: if the patient had stepwise increase in the disability following each relapse, until the time of death.

(3) Relapsing progressive: if the initial pattern was remitting relapsing and subsequently was followed by a progressively increasing disability until death.

(4) Progressive: if the disability increased relentlessly from onset until death.

Thanks to the completeness of information about urinary and psychiatric symptoms in the majority of cases, the frequency and timing of these symptoms could be correlated in detail with the survival period.

The life expectancy of the patients was compared with that of the Scottish general population using life tables. ${ }^{31}$

Information about the cause of death was obtained from copies of death certificates automatically retrieved from the central register office in Edinburgh; this was cross-checked with the information in the hospital case notes, in the annual mortality print-out of the Registrar General of Scotland, and in some cases with the general practitioners' records. 
Table 1 Multiple sclerosis deaths between December 1970 and December 1980 in the Grampian region

\begin{tabular}{|c|c|c|c|c|c|c|c|c|c|c|c|c|}
\hline Years & $\begin{array}{l}\text { Dec } \\
1970\end{array}$ & 1971 & 1972 & 1973 & 1974 & 1975 & 1976 & 1977 & 1978 & 1979 & 1980 & Total \\
\hline $\begin{array}{l}\text { Males } \\
\text { Females } \\
\text { Total } \\
\text { Source of Information }\end{array}$ & $\begin{array}{l}0 \\
3 \\
3\end{array}$ & $\begin{array}{r}5 \\
16 \\
21\end{array}$ & $\begin{array}{l}11 \\
10 \\
21\end{array}$ & $\begin{array}{r}12 \\
7 \\
19\end{array}$ & $\begin{array}{r}5 \\
18 \\
23\end{array}$ & $\begin{array}{r}5 \\
14 \\
19\end{array}$ & $\begin{array}{l}15 \\
12 \\
27\end{array}$ & $\begin{array}{r}3 \\
9 \\
12\end{array}$ & $\begin{array}{r}8 \\
16 \\
24\end{array}$ & $\begin{array}{r}8 \\
9 \\
17\end{array}$ & $\begin{array}{l}10 \\
20 \\
30\end{array}$ & $\begin{array}{r}82 \\
134 \\
216\end{array}$ \\
\hline $\begin{array}{l}\text { Registrar General Annual Returns } \\
\text { Death Certificate copies supplied by RG }\end{array}$ & - & 10 & 5 & 9 & 5 & 15 & 19 & 10 & 19 & 13 & 19 & \\
\hline $\begin{array}{l}\text { Office (Edinburgh) } \\
\text { Local source including autopsy reports } \\
\text { and GP questionnaires }\end{array}$ & - & 7 & 11 & 10 & 15 & 3 & 5 & 2 & 2 & 0 & 3 & \\
\hline
\end{tabular}

The number of deaths per year between 1970 and source of information about these is summarised in table 1 .

The degree of disability close to death was evaluated using McAlpine's disability grading; ${ }^{32}$ this was tabulated against the cause of death, in an attempt to establish the proportion of patients in whom multiple sclerosis was the principal cause of death.

\section{Results}

Survival by sex

There were 134 females and 82 males. The mean delay between onset and the diagnostic hospital visit was 5.6 years $(\mathrm{SD} \pm 6.3)$ for females and 6.7 years $(\mathrm{SD} \pm$ 7.9) for males. The mean survival for all patients (200) was 24.5 years, females survived slightly longer $(25 \cdot 7$ years) compared with males (23.5 years). This

difference between the two was statistically not significant.

\section{Survival compared with the Scottish general population}

The life expectancy of the patients differed significantly compared with age matched controls from the general population. The following differences emerged (fig 2: I-V).

(1) Survival at 10 years after onset was only minimally reduced for all patients except those with onset over the age of 50 years, in whom it was reduced by $44 \%$ for the males and $22 \%$ for the females compared to age matched controls (fig 2-V).

(2) The majority of the patients with onset of the

III

30-39
IV

40-49
V

\section{0-65}
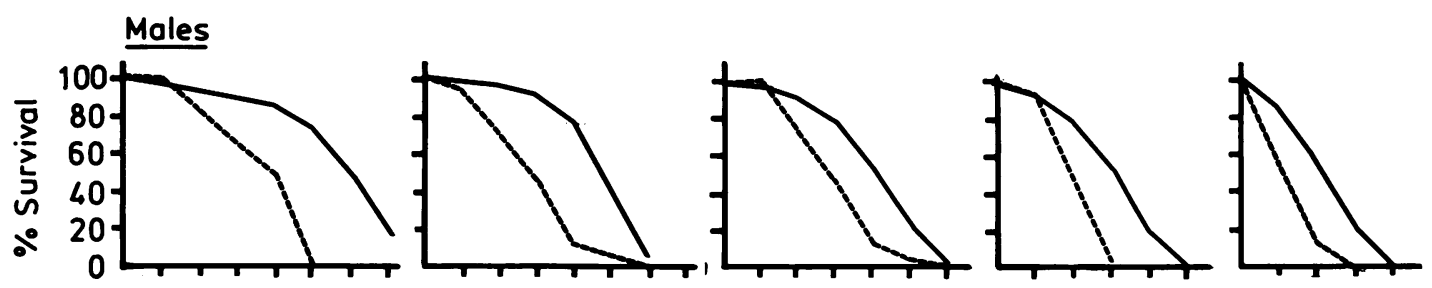

\section{Scottish pop.}

Females

\section{-.- Patients}
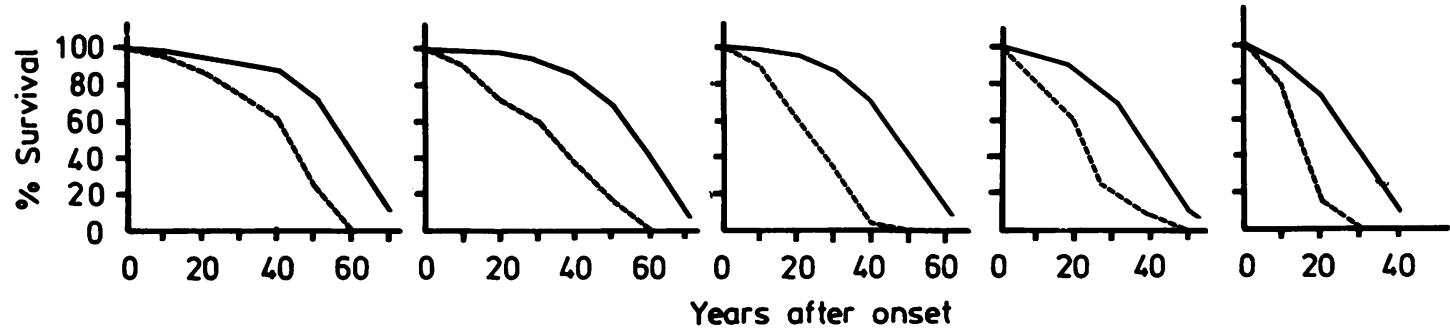

Fig 2 I-V Survival curves for male and female patients with onset at different ages compared with those of the age matched general population. 
Table 2 Probability of survival after onset of the disease

\begin{tabular}{|c|c|c|c|c|c|c|}
\hline \multirow[b]{3}{*}{ Duration of the disease } & \multicolumn{6}{|c|}{ Cumulative probability of survival } \\
\hline & \multicolumn{3}{|l|}{ Males } & \multicolumn{3}{|l|}{ Females } \\
\hline & Observed & Expected & $O-E$ & Observed & Expected & $O-E$ \\
\hline $\begin{array}{rr}<10 & (25) \\
10-19(35) \\
20-29(45) \\
30-39(55) \\
40-49(65) \\
50-59(75) \\
60-65(85)\end{array}$ & $\begin{array}{l}0.87 \\
0.53 \\
0.30 \\
0.10 \\
0.04 \\
0.01 \\
0\end{array}$ & $\begin{array}{l}0.98 \\
0.96 \\
0.94 \\
0.89 \\
0.77 \\
0.52 \\
0.20\end{array}$ & $\begin{array}{l}0.11 \\
0.43 \\
0.64 \\
0.79 \\
0.74 \\
0.51 \\
0.20\end{array}$ & $\begin{array}{c}0.86 \\
0.57 \\
0.36 \\
0.17 \\
0.06 \\
0 \\
0\end{array}$ & $\begin{array}{l}0.98 \\
0.96 \\
0.95 \\
0.92 \\
0.84 \\
0.69 \\
0.40\end{array}$ & $\begin{array}{l}0.12 \\
0.39 \\
0.59 \\
0.75 \\
0.78 \\
0.69 \\
0.40\end{array}$ \\
\hline
\end{tabular}

O-E = observed-expected.

(N.B. Figures in brackets in column one represent mean age at onset.)

disease after the age of 50 years died within 20 years, and all were dead by 30 years. This was in contrast to a $22 \%$ survival for males and $44 \%$ for females from the age matched general population (fig 2-V).

(3) The greatest impact of the disease was noted in the age group 40-49 years at onset to which more than a quarter of the patients $(27 \%)$ belonged (fig $2-I V$ ). Here, only $26 \%$ of the females and $5 \%$ of the males were alive at 30 years after onset compared with $70 \%$ of the females and $60 \%$ of the males from age matched general population.

The probability of survival $(\mathrm{P})$ for the entire sample was compared with that of the Scottish general population aged 10-20 years between 1930-32 using the Scottish Life Tables (table 2). The probability of survival at 10 years for a male patient aged 25 years at onset was of the order of $87 \%$ compared with an

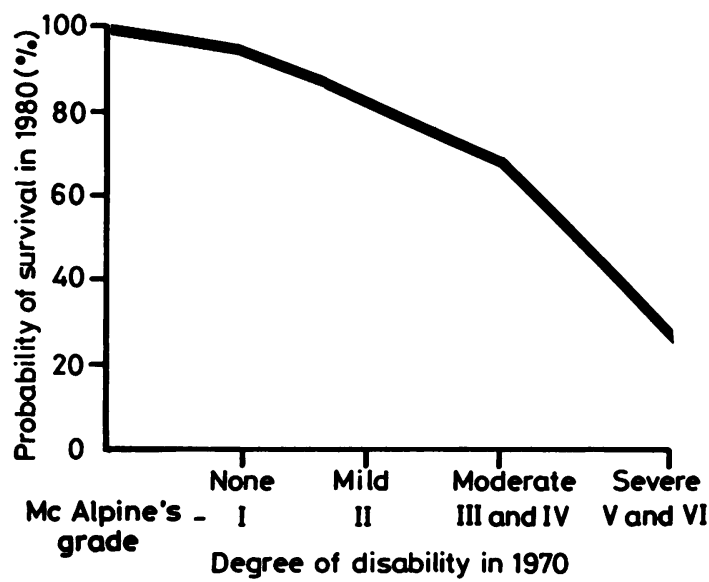

Fig 3 Probability of survival based on disability at a point in time. expected figure of $98 \%$; the respective figures for females were $86 \%$ and $98 \%$. The probability of such a patient surviving till the age of 65 years was only $4 \%$ in males and $6 \%$ in females; the comparative figures for a person from the age matched general population was $77 \%$ in males and $84 \%$ in females.

Predicted $(P)$ survival based on disability at a point in time

Disability (using McAlpines grades) ${ }^{32}$ was known for 676 patients living in the Grampian region in 1970. This was plotted against the proportion of patients surviving till 1980 (fig 3).

(1) Ninety four per cent of those free of any disability in 1970 were alive 10 years later.

(2) Of those with mild disability in the year 1970 (McAlpine's Grade II) $80 \%$ were alive at 10 years.

(3) Of those with moderate disability (Grades III-IV) $69 \%$ were alive at 10 years.

(4) And, of those who had severe disability in 1970 (Grades V-VI) only $28 \%$ were alive at 10 years.

CORRELATION BETWEEN PERIOD OF SURVIVAL AND VARIOUS CLINICAL FEATURES

Age at onset and sex by survival

The survival period was inversely linked to the age at onset (table 3). This relationship between the two was highly significant on independent or combined analysis for either sex $(p<0.001)$. Females on the whole survived slightly longer (except those with onset between the ages of 30-39 years); the differences between males and females in different age groups however were statistically not significant.

Pattern of initial symptoms by survival period

Severity of the initial lesion was not known in a sizeable number. Patients with an initial brainstem lesion survived longer compared with those with lesions 
Table 3 Survival after onset of the disease by age and sex

\begin{tabular}{|c|c|c|c|c|c|c|c|c|c|c|c|c|}
\hline \multirow{3}{*}{$\begin{array}{l}\text { Disease } \\
\text { duration } \\
\text { (years) }\end{array}$} & \multicolumn{10}{|c|}{ Age at onset of the disease (years) } & & \\
\hline & \multicolumn{2}{|l|}{20} & \multicolumn{2}{|l|}{$20-29$} & \multicolumn{2}{|l|}{$30-39$} & \multicolumn{2}{|l|}{$40-49$} & \multicolumn{2}{|l|}{$>50$} & \multicolumn{2}{|l|}{ Total } \\
\hline & $M$ & $F$ & $M$ & $F$ & $M$ & $F$ & $M$ & $F$ & $M$ & $F$ & $M$ & $F$ \\
\hline$<10$ & $16 \cdot 7$ & 0 & $5 \cdot 9$ & $8 \cdot 3$ & 0 & $8 \cdot 7$ & $5 \cdot 3$ & $20 \cdot 0$ & 43.7 & $23 \cdot 8$ & $13 \cdot 2$ & 13.8 \\
\hline $10-19$ & $16 \cdot 7$ & $12 \cdot 5$ & $23 \cdot 5$ & $19 \cdot 4$ & $27 \cdot 8$ & $30 \cdot 4$ & $47 \cdot 4$ & $22 \cdot 9$ & 43.7 & 61.9 & $34 \cdot 2$ & $29 \cdot 3$ \\
\hline $20-29$ & 0 & $12 \cdot 5$ & $23 \cdot 5$ & $11 \cdot 1$ & 16.7 & $26 \cdot 1$ & $42 \cdot 1$ & $31 \cdot 4$ & $12 \cdot 5$ & $14 \cdot 3$ & $22 \cdot 4$ & $20 \cdot 3$ \\
\hline $30-39$ & $16 \cdot 7$ & $12 \cdot 5$ & $35 \cdot 3$ & 25.0 & $36 \cdot 8$ & $30 \cdot 4$ & $5 \cdot 3$ & 20.0 & 0 & 0 & 19.7 & $19 \cdot 5$ \\
\hline$>40$ & $50 \cdot 0$ & $62 \cdot 5$ & $11 \cdot 8$ & $36 \cdot 1$ & 16.7 & $4 \cdot 3$ & 0 & 5.7 & 0 & 0 & 10.5 & $17 \cdot 1$ \\
\hline Total & $\begin{array}{l}100 \\
(6)\end{array}$ & $\begin{array}{l}100 \\
(8)\end{array}$ & $\begin{array}{l}100 \\
(17)\end{array}$ & $\begin{array}{l}100 \\
(36)\end{array}$ & $\begin{array}{l}100 \\
(18)\end{array}$ & $\begin{array}{l}100 \\
(23)\end{array}$ & $\begin{array}{l}100 \\
(19)\end{array}$ & $\begin{array}{l}100 \\
(35)\end{array}$ & $\begin{array}{l}100 \\
(16)\end{array}$ & $\begin{array}{l}100 \\
(21)\end{array}$ & $\begin{array}{l}100 \\
(76)\end{array}$ & $\begin{array}{l}100 \\
(123)\end{array}$ \\
\hline
\end{tabular}

N.B. 16 patients with unknown age at onset and one with unknown duration not shown.

Males: $\chi^{2}=47.588, \mathrm{Df}=16 \mathrm{p}<0.001$.

Females: $\chi^{2}=51.519$, Df $=16 \mathrm{p}<0.0001$

All: $\chi^{2}=80.82$, Df $=16 \mathrm{p}<0.001$.

Table 4 Period of survival after onset by pattern of initial symptoms \% (in brackets are actual numbers with each symptom)

\begin{tabular}{|c|c|c|c|c|c|c|c|}
\hline $\begin{array}{l}\text { Disease } \\
\text { duration } \\
\text { (years) }\end{array}$ & $\begin{array}{l}\text { Cerebral } \\
\text { disturbance } \\
(10)\end{array}$ & $\begin{array}{l}\text { Retrobulbar } \\
\text { neuritis } \\
(40)\end{array}$ & $\begin{array}{l}\text { Brainstem } \\
\text { disturbance } \\
(36)\end{array}$ & $\begin{array}{l}\text { Pyramidal } \\
\text { disturbance } \\
(103)\end{array}$ & $\begin{array}{l}\text { Cerebellar } \\
\text { disturbance } \\
(30)\end{array}$ & $\begin{array}{l}\text { Sensory } \\
\text { disturbance } \\
\text { (54) }\end{array}$ & $\begin{array}{l}\text { Urinary } \\
\text { disturbance } \\
(12)\end{array}$ \\
\hline$<10$ & 0 & $12 \cdot 5$ & $5 \cdot 6$ & 15.5 & $20 \cdot 0$ & $22 \cdot 2$ & 16.7 \\
\hline $10-19$ & $70 \cdot 0$ & $25 \cdot 0$ & $19 \cdot 4$ & $28 \cdot 2$ & $43 \cdot 3$ & $31 \cdot 5$ & $41 \cdot 7$ \\
\hline $20-29$ & $30 \cdot 0$ & $20 \cdot 0$ & $27 \cdot 8$ & $23 \cdot 3$ & $23 \cdot 3$ & $16 \cdot 7$ & 16.7 \\
\hline $30-39$ & 0 & $25 \cdot 0$ & 19.4 & $22 \cdot 3$ & 10.0 & 13.0 & $8 \cdot 3$ \\
\hline$>40$ & 0 & $17 \cdot 5$ & $27 \cdot 8$ & 10.7 & $3 \cdot 3$ & $16 \cdot 7$ & $16 \cdot 7$ \\
\hline Total \% & 100 & 100 & 100 & 100 & 100 & 100 & 100 \\
\hline & 8.47 & 1.56 & $10 \cdot 24$ & 4.05 & $7 \cdot 72$ & 6.90 & 1.58 \\
\hline$\tilde{D f}$ & 2 & 4 & 4 & 4 & 4 & 4 & 4 \\
\hline P value & 0.01 & 0.81 & 0.03 & 0.39 & 0.1 & $0 \cdot 14$ & 0.81 \\
\hline
\end{tabular}

N.B. 16 patients with uncertain pattern of initial symptoms or duration of the disease are not shown. More than one symptom occurred in many patients ( $\chi^{2}$ analysed on actual numbers).

Table 5 Survival by onset to first relapse interval

\begin{tabular}{|c|c|c|c|c|c|c|c|}
\hline \multirow{2}{*}{$\begin{array}{l}\text { Disease } \\
\text { duration } \\
\text { (years) }\end{array}$} & \multicolumn{6}{|c|}{ Interval between onset - first relapse $\%$} & \multirow[b]{2}{*}{ Total } \\
\hline & $<6$ months & $7-12$ months & $1-2$ years & $3-4$ years & 5-9 years & $>10$ years & \\
\hline $\begin{array}{l}<10 \\
10-19 \\
20-29 \\
30-39 \\
>40 \\
\text { Total }\end{array}$ & $\begin{array}{r}33 \cdot 3 \\
14 \cdot 3 \\
11 \cdot 1 \\
3.6 \\
4 \cdot 3 \\
11 \cdot 4\end{array}$ & $\begin{array}{r}16 \cdot 7 \\
11 \cdot 9 \\
18 \cdot 5 \\
7 \cdot 1 \\
4 \cdot 3 \\
11.4\end{array}$ & $\begin{array}{l}50 \cdot 0 \\
40 \cdot 5 \\
37 \cdot 0 \\
25 \cdot 0 \\
21 \cdot 7 \\
34 \cdot 1\end{array}$ & $\begin{array}{c}0 \\
19 \cdot 0 \\
18 \cdot 5 \\
14 \cdot 3 \\
4 \cdot 3 \\
13 \cdot 6\end{array}$ & $\begin{array}{l}0 \\
11.9 \\
14.8 \\
25.0 \\
21.7 \\
15.9\end{array}$ & $\begin{array}{l}0 \\
2 \cdot 4 \\
0 \\
25 \cdot 0 \\
43 \cdot 5 \\
13 \cdot 6\end{array}$ & $\begin{array}{l}100(12) \\
100(42) \\
100(27) \\
100(28) \\
100(23) \\
100(132)\end{array}$ \\
\hline
\end{tabular}

N.B. Patients with progressive pattern (31), those with single episode and those in whom precise duration of the disease was unknown are not shown. $\chi^{2}=49.700$, Df $=20 \mathrm{p}<0.001$ ( $\chi^{2}$ analysed on actual numbers).

Table 6 Survival period by frequency and timing of psychiatric and urinary symptoms

\begin{tabular}{|c|c|c|c|c|c|c|c|}
\hline \multirow[b]{2}{*}{$\begin{array}{l}\text { Duration of the } \\
\text { disease (years) }\end{array}$} & \multicolumn{4}{|c|}{ Frequency and timing of psychiatric symptoms (\%) } & \multicolumn{3}{|c|}{ Frequency and timing of urinary symptoms (\%) } \\
\hline & None & $\begin{array}{l}\text { Occurrence } \\
\text { at onset }\end{array}$ & $\begin{array}{l}\text { Occurrence } \\
\text { within } \\
\text { l0 years }\end{array}$ & $\begin{array}{l}\text { Occurrence } \\
\text { after } \\
10 \text { years }\end{array}$ & None & $\begin{array}{l}\text { Occurrence } \\
\text { within } 10 \\
\text { years of onset }\end{array}$ & $\begin{array}{l}\text { Occurrence } \\
\text { after } 10 \text { years } \\
\text { of onset }\end{array}$ \\
\hline $\begin{array}{l}<10 \\
10-19 \\
20-29 \\
30-39 \\
>40 \\
\text { Total }\end{array}$ & $\begin{array}{c}11 \cdot 0 \\
25 \cdot 6 \\
7 \cdot 1 \\
25 \cdot 6 \\
20 \cdot 7 \\
100(82)\end{array}$ & $\begin{array}{c}0 \\
77 \cdot 8 \\
22 \cdot 2 \\
0 \\
0 \\
100(9)\end{array}$ & $\begin{array}{c}34 \cdot 0 \\
42 \cdot 5 \\
14 \cdot 9 \\
6 \cdot 4 \\
2 \cdot 1 \\
100(47)\end{array}$ & $\begin{array}{c}0 \\
19 \cdot 2 \\
31 \cdot 9 \\
29 \cdot 8 \\
19 \cdot 2 \\
100(47)\end{array}$ & $\begin{array}{c}17 \cdot 9 \\
32 \cdot 1 \\
14 \cdot 3 \\
21 \cdot 4 \\
14 \cdot 2 \\
100(28)\end{array}$ & $\begin{array}{c}20 \cdot 2 \\
40 \cdot 4 \\
20 \cdot 2 \\
12 \cdot 8 \\
6 \cdot 4 \\
100(94)\end{array}$ & $\begin{array}{c}0 \\
15 \cdot 4 \\
24 \cdot 6 \\
30 \cdot 8 \\
29 \cdot 2 \\
100(65)\end{array}$ \\
\hline
\end{tabular}


Table 7 Survival by course of the disease

\begin{tabular}{|c|c|c|c|c|}
\hline \multirow{2}{*}{$\begin{array}{l}\text { Disease duration } \\
\text { (years) }\end{array}$} & \multicolumn{3}{|l|}{ Course of the disease } & \multirow[b]{2}{*}{ Total $\%$} \\
\hline & Relapsing cumulative $\%$ & Relapsing progressive $\%$ & Progressive $\%$ & \\
\hline $\begin{aligned} &< 10 \\
& 10-19 \\
& 20-29 \\
& 30-39 \\
&>40\end{aligned}$ & $\begin{array}{c}6 \cdot 0 \\
21 \cdot 7 \\
24 \cdot 1 \\
25 \cdot 3 \\
22 \cdot 9 \\
100(83)\end{array}$ & $\begin{array}{c}11 \cdot 5 \\
33 \cdot 3 \\
19 \cdot 2 \\
23 \cdot 1 \\
12 \cdot 8 \\
100(78)\end{array}$ & $\begin{array}{c}30 \cdot 0 \\
46 \cdot 7 \\
20 \cdot 0 \\
3 \cdot 3 \\
0 \\
100(30)\end{array}$ & $\begin{array}{c}12 \cdot 0 \\
30 \cdot 4 \\
21 \cdot 5 \\
20 \cdot 9 \\
15 \cdot 2 \\
100(191)\end{array}$ \\
\hline
\end{tabular}

$\chi^{2}=29.39, \mathrm{Df}=8, \mathrm{p}<0.001$ (25 cases with details of course or survival period unavailable are not shown). ( $\chi^{2}$ analysed on actual numbers).

anywhere else in the CNS $(\mathrm{p}=0.03)$. Those with initial isolated optic neuritis followed next in the order of prognosis. Patients with initial sensory or cerebellar symptoms seemed to survive the shortest; a high proportion of the former, however, also had coexistent pyramidal deficit. However, except those with brainstem lesion at onset, the difference in the survival between all other groups was statistically not significant (table 4).

\section{Onset to first relapse interval by survival}

A highly significant relationship was noted between the two ( $p<0.001)$. Those with a short interval $(<1$ year) had a significantly reduced life expectancy. Of the 12 patients who died within 10 years of the onset, a third had the first relapse within 6 months and the remaining two thirds within 2 years. In contrast, of the 23 patients who had survived beyond 40 years only $4 \%$ had the first relapse within 6 months and nearly half the patients had an interval exceeding 10 years (table 5).

\section{Frequency of psychiatric and urinary symptoms by survival}

Information about occurrence of significant psychiatric and urinary symptoms (that is, those warranting assessment in a hospital) was available in the case of 188 and 191 patients respectively. One hundred and four $(55 \%)$ needed inpatient psychiatric care and $162(84 \%)$ had urinary symptoms at some stage. No significant difference was noted in the survival between those with and without psychiatric symptoms $(\mathrm{p}>0 \cdot 1)$. A highly significant difference was, however, noted between those with such symptoms at different stages of the disease. Those with psychiatric symptoms occurring at onset or within 10 years of it had a significantly reduced survival compared to those without them (table 6).

An almost similar pattern was also seen with regard to urinary symptoms. Patients with lasting urinary symptoms within 10 years of onset had significantly reduced survival compared with those having them later on $(p<0.001)$ (table 6$)$.
Survival by course of the disease

Those with a relapsing remitting disease survived the longest, followed by those with initially relapsing and later progressive disease. Patients who had a steadily increasing progressive disability from the start had the shortest survival $(p<0.001)$ (table 7).

The cerebrospinal fluid was analysed in two thirds of the cases. Changes in any of the CSF parameters had no relationship with the survival period.

\section{CAUSE OF DEATH}

As shown in table 1, information about all multiple sclerosis deaths in the region was collected from many different sources. A third of the patients died at home and the remaining two thirds in the hospital; only a third of the patients needed long-term hospital care exceeding 3 months. Out of the 67 patients who needed long-term inpatient care, $52 \%$ required it for less than 10 months, $25 \%$ between $10-19$ months, and the remaining $26 \%$ for a period exceeding 20 months, only three patients-needed hospital care exceeding 3 years.

Sixty two per cent (132/214) died from complications directly related to multiple sclerosis, $12 \%$ from haematological or systemic malignant disease, $19 \%$ from atheromatous disease of the coronary,

Table 8 Principal cause of death and preterminal degree of disability

\begin{tabular}{|c|c|c|c|c|c|c|c|c|}
\hline \multirow[b]{2}{*}{ Cause of death } & \multicolumn{8}{|c|}{ Degree of disability (McAlpine's grading) } \\
\hline & 1 & 2 & 3 & 4 & 5 & 6 & 0 & Total \\
\hline \multicolumn{9}{|l|}{ Multiple sclerosis } \\
\hline and related & 0 & 0 & 0 & 1 & 10 & 113 & 7 & 132 \\
\hline Malignancies & 2 & 8 & 3 & 5 & 3 & 2 & 2 & 25 \\
\hline Cardiovascular & 1 & 2 & 2 & 2 & 9 & 11 & 14 & 41 \\
\hline \multicolumn{9}{|l|}{$\begin{array}{l}\text { Primary } \\
\text { pulmonary }\end{array}$} \\
\hline disease & 0 & 1 & 1 & 1 & 0 & 2 & 2 & 7 \\
\hline Gastrointestinal & 0 & 0 & 0 & $i$ & 3 & $\overline{1}$ & 0 & 5 \\
\hline $\begin{array}{l}\text { Miscellaneous } \\
\text { and unknown }\end{array}$ & 0 & 0 & 1 & 1 & 1 & 0 & 3 & 6 \\
\hline Total & 3 & 11 & 7 & 11 & 26 & 129 & 28 & 216 \\
\hline
\end{tabular}


cerebral or peripheral vessels, and $5 \%$ from other miscellaneous conditions. The cause of death was unknown for two patients. The degree of disability nearer the time of death and the individual causes are listed in table 8.

Out of the various malignancies, bronchogenic carcinoma occurred most frequently; this was in keeping with the general trend in the west. Frequency of diseases in multiple sclerosis patients and those in the general population could not be compared owing to lack of precise incidence figures for most diseases in the community; no undue excess of any particular disease was however observed amongst the patients. Out of the 132 patients who died due to complications of multiple sclerosis, in the case of 31 one additional cause, and in nine two additional causes were also responsible for early death.

The terminal event was known in 151 patients; $55 \%$ died of bronchopneumonia, $11 \%$ had confirmed septicaemia, $15 \%$ had myocardial infarction, $4 \%$ had pulmonary embolism diagnosed clinically, and the remaining $15 \%$ died of other miscellaneous conditions such as gastrointestinal bleeding (1), gangrene of the legs (1), pneumothorax (1), inhalation asphyxia (5) etc. The rather low incidence of pulmonary embolism was certainly an underestimate, as the majority of patients with terminal respiratory illness did not have investigations such as ventilation perfusion scan and were thought as having bronchopneumonia only on the grounds of clinical and plain radiological findings.

The necropsy rate was rather low $(16 \%)$, similar to the general trend in western centres. The clinical diagnosis of multiple sclerosis was confirmed in all the $\mathbf{3 5}$ cases undergoing necropsy.

\section{Discussion}

In most studies published prior to the sixties, survival period after onset of multiple sclerosis has been reported to range between $10-12$ years. ${ }^{1-5}$ Müller $^{6}$ in his retrospective analysis of 793 patients found a figure ranging between $16-34$ years. Allison ${ }^{10}$ on follow-up of an epidemiological sample of 40 patients from North Wales after an interval of 20 years noted a mean survival of 20 years. In three series reported from North America in the year 1950, a survival period ranging between 13-17 years was noted. ${ }^{7-9}$ In a prospective follow-up of a selected sample of multiple sclerosis patients from a large hospital source, McAlpine ${ }^{11}$ reported a survival period of only 11 years. All the above studies were carried out in the pre-antibiotic era, and with the exception of Allison's, ${ }^{10}$ represented hospital based series biased towards the severe end of the disease spectrum.

A more realistic figure, as noted presently, and also in many of the recently published series derived from a prevalence source, ${ }^{121516}$ is around 25 years. A cautionary note about the current figure, and those in the studies from Denmark, ${ }^{12}$ the Mayo Clinic, ${ }^{15}$ and Iceland ${ }^{16}$ is that all of these probably included a spuriously higher proportion of the poor survivor, as none represented follow-up of an unselected cohort of multiple sclerosis cases observed from the onset to death, and the true mean survival figure may well be between 25-30 years. Kurtzke et al $^{17}$ estimated a survival period exceeding 30 years in their series of US male veterans. Two notable exceptions to the current trend in the west are the figures from Winnipeg ${ }^{13}$ and Israel. ${ }^{23}$ In the former, a mean survival figure of $17 \cdot 7$ years and in the latter that of $17 \cdot 4$ years was observed. A shorter life expectancy in general amongst the male population in the country, and an element of selection in the age structure of the immigrant population were given as the likely reasons for the low figure from Israel; ${ }^{23}$ no explanation for the Canadian figure was however offered. ${ }^{13}$

Life expectancy, of patients with disease onset at different ages has been compared with age matched controls in only two previous studies. ${ }^{1520}$ Conclusions of the present study bear a striking similarity to those drawn in the Rochester series. ${ }^{15}$ On the other hand, overall survival curves of patients have been compared with those of the general population, without sub-division into different age groups in three previous studies. ${ }^{132123}$ In Winnipeg ${ }^{13}$ a reduction in the life expectancy of the order of $17 \%$ at 5 years and $31 \%$ at 11 years in the case of males and slightly better figures in the case of females were noted. Kurtzke et al $^{21}$ noted an $8 \%$ reduction at 10 years and $21 \%$ at 20 years while in Israel $^{23}$ a reduction in the life expectancy of the order of $11 \%$ at 10 years after onset was noted. Findings of the present study confirm the generally held belief that multiple sclerosis shortens the life expectancy irrespective of the age at onset of the disease, maximum reduction compared with age matched controls being noted amongst those with onset of the disease over the age of $\mathbf{4 0}$ years.

With few exceptions ${ }^{611323435}$ clinical features influencing the prognosis have been correlated in most studies with the disability at a point in time amongst the living, rather than with the total period of survival amongst those observed till death. During the present investigation both groups were studied separately, and the results for those living in the region in December 1980 will be published separately.

In the present study no significant difference in the life expectancy was noted between the sexes; this is in general agreement with findings in most other centres.

As noted by others 2233335 and discussed above, age at onset clearly had an influence on the period of survival. Amongst the initial symptoms cerebellar 
ataxia with or without motor deficit signified worse prognosis, a universal agreement on this finding seems to exist in the literature. ${ }^{61135}$ Psychiatric symptoms at onset or within 10 years or significant urinary symptoms within 10 years were both noted to be associated with reduced life expectancy in the present study. Similar findings have not been previously reported in any larger series. The association between a benign prognosis, depicted by. longer survival and occurrence of isolated retrobulbar neuritis ${ }^{1134}$ or isolated brainstem lesion ${ }^{16}$ at onset has been recognised previously. There are no published series showing poor prognosis amongst patients with symptoms due to either of these lesions although in a number of studies a lack of similar association has been noted.

The association between a significantly reduced survival and a short onset - relapse interval has not been previously documented. However, early severe disability, another indicator of disease severity, has been clearly shown to be linked with a short interval at least in two studies. ${ }^{1836}$

Universal agreement exists in the literature about the association between poor prognosis in terms of significantly reduced survival and a progressive course from the start of the disease. ${ }^{6911} 14$ Leibowitz et $a l^{14}$ however, felt that it was the late age at onset rather than the progressive course (both of which often coexist), which was the factor responsible for the reduced survival.

Disability observed at a point in time has been found to be a useful means of predicting long term survival. ${ }^{121620}$ MacLean and Berkson ${ }^{20}$ in a large series from the Mayo Clinic noted that, of those working and walking normally at the time of the diagnosis, $96 \%$ were alive at 5 years and $88 \%$ at 10 years; comparative figures for those who were significantly disabled at the time of diagnosis, were, however, not reported. Hyllested ${ }^{12}$ observed that, of the 886 patients who were free of any disability at the time of the first survey, $93 \%$ were alive at 10 years, compared with only $36 \%$ of those with severe disability. Figures from Iceland ${ }^{16}$ were similar with $98 \%$ of those without disability at the time of the first survey being alive at 14 years compared to only $27 \%$ of those with severe disability. Present figures are in striking agreement with the latter two studies, and clearly support the view that disability at a point in time can also form a useful measure of predicting long term survival.

Amongst the various series in the literature, where causes of death in patients suffering from multiple sclerosis have been analysed, complications directly related to the disease per se were thought responsible for the mortality in $64-68 \%$ of the patients; ${ }^{62123-25}$ the present figures are similar.
With the exception of an uncontrolled series of 41 necropsied cases where an excess of malignant diseases amongst multiple sclerosis patients was noted ${ }^{26}$ no undue excess of any particular disease has been found ${ }^{13212527}$ the present findings are in agreement with the latter series.

In conclusion, in this largest unselected series of multiple sclerosis patients derived from a prevalence source and observed till death, a mean survival period of 24.5 years was noted. There was no significant difference in the prognosis between the sexes. A significant reduction in the long term survival was noted amongst all patients compared with matched controls, with the greatest impact noticeable amongst those with onset over the age of 40 years. Relationship between a number of clinical features at onset and the disease prognosis noted previously was confirmed. Onset to first relapse interval and degree of disability at a point in time form useful indicators of long term prognosis of the disease.

I am grateful to Miss W Hope for typing the manuscript.

\section{References}

1 Bramwell B. The prognosis in disseminated sclerosis, duration in two hundred cases of disseminated sclerosis. Edin Med J 1917;18:16-23.

2 Curtius F. Die Prognose der multiplen Sklerose. Deutsche Med Wchnschr 1941;67:461-3.

3 Gram HC. Den disseminerede Skleroses forekomst $i$ Danmark. Ugesk $f$ Laeger 1934;96:823-5.

4 Brain WR. Prognosis of Disseminated Sclerosis. Lancet 1936;2:866-7.

5 Sallstrom T. Das Vorkommen und die Verbreitung der multiplen Sklerose in Schweden. Zur geographischen pathologie der multiplen sklerose. Acta Med Scand 1942;suppl 137:1-141.

6 Müller R. Studies on disseminated sclerosis with special reference to symptomatology, course and prognosis. Acta Med Scand 1949;133, suppl.222.

7 Ipsen J. Life expectancy and probable disability in multiple sclerosis. N Engl J Med 1950;243:909-13.

8 Carter S, Sciarra D, Merritt HH. The course of multiple sclerosis as determined by autopsy proven cases. Assoc Res Nerv Dis Proc 1950;28:471-511.

9 Lazarte JA. Multiple sclerosis: prognosis for ambulatory and nonambulatory patients. Assoc Res Nerv Dis Proc 1950;28:512-23.

10 Allison RS. Survival in disseminated sclerosis: a clinical study of a series of cases first seen twenty years ago. Brain 1950;73:103-20.

11 McAlpine D. The benign form of multiple sclerosis. A study based on 241 cases seen within three years of onset and followed up until the tenth year or more of the disease. Brain 1961;84:186-203.

12 Hyllested K. Lethality, duration and mortality of disseminated sclerosis in Denmark. Acta Psych Neuro Scand 1961;36(4):553-64. 
13 Stazio A, Kurland LT, Bell LG, Saunders MG, Rogot E. Multiple sclerosis in Winnipeg, Manitoba: methodological consideration of epidemiological survey. $J$ Chronic Dis 1964;17:415-38.

14 Leibowitz V, Kahana E, Alter M. Survival and death in multiple sclerosis. Brain 1969;92:115-30.

15 Percy AK, Nobrego FT, Okazaki H, Glatter E, Kurland LT. Multiple sclerosis in Rochester, Minn. Arch Neurol 1971;25:105-11.

16 Gudmundsson KR. Clinical studies of multiple sclerosis in Iceland-a follow-up of previous survey and reappraisal. Acta Neurol Scand 1971;47:suppl 48:1-78.

17 Kurtzke JF, Beebe GW, Nagler B, Kurland L, Auth TL. Studies on the natural history of multiple sclerosis 8. Early prognostic features of the later course of the illness. J Chronic Dis 1977;30:819-30.

18 Confavreux C, Aimard G, Devic M. Course and prognosis of multiple sclerosis assessed by the computerised data processing of 349 patients. Brain 1980; 103:281-300.

19 Matthews WB. Course and Prognosis. In: Matthews WB, Acheson ED, Batchelor JR, Weller RO, eds. McAlpine's Multiple Sclerosis. Edinburgh: Churchill Livingstone, 1985:60.

20 Maclean AR, Berkson J. Mortality and disability in multiple sclerosis-a statistical estimate of prognosis. JAMA 1951;146:1367-9.

21 Kurtzke JF, Beebe GW, Nagler B, Nefzger MD, Auth TL, Kurland LT. Studies on the natural history of multiple sclerosis. V. Longterm survival in young men. Arch Neurol 1970;22:215-25.

22 Visscher B, Liu KS, Clark A, Detels R, Malmgren M, Dudley JP. Onset symptoms as predictors of mortality and disability in multiple sclerosis. Acta Neurol Scand 1984;70:321-8.

23 Leibowitz V, Alter M. Multiple Sclerosis: Clues to its Causes. Amsterdam: North Holland Publishing Co, 1973.

24 Reinhold M. Prognosis in disseminated sclerosis. Br Med
$J$ 1950;1:160-2.

25 Allen IV, Millar JHD, Hutchinson MJ. General disease in 120 necropsy-proven cases of multiple sclerosis. Neuropathol Appl Neurobiol 1978;4:279-84.

26 Zimmermann HM, Netsky MG. The pathology of multiple sclerosis. Research Publication of the Assoc Res New Ment Diseases 1950;28:271-312.

27 Lumsden CE. Pathology of multiple sclerosis. In: Vinken PJ, Bruym GW, eds. Handbook of Clinical Neurology. Amsterdam: North Holland Publishing Co, 1970;9:232-3.

28 Shepherd DI, Downie AW. Prevalence of multiple sclerosis in North-East Scotland. $\mathrm{Br} \mathrm{Med} J$ 1978;2:314-6.

29 Shepherd DI, Downie AW. A further prevalence study of multiple sclerosis in North-East Scotland. J Neurol Neurosurg Psychiatry 1980;43:310-5.

30 Downie AW, Phadke JG. Multiple sclerosis in the North-East of Scotland. Scottish Health Bulletin 1984;42/3:151-6.

31 Scottish Life Tables 1970-72. First supplement to the 123rd annual report of the Registrar General for Scotland. Edinburgh: HM Stationery Office, 1977.

32 McAlpine D, Compston N. Some aspects of the natural history of disseminated sclerosis. I. The incidence, course and prognosis. II. Factors affecting the onset and course. $Q J$ Med 1952;21:135-67.

33 Müller R. Course and prognosis of disseminated sclerosis in relation to age of onset. Arch Neurol Psychiatr 1951;66:561-70.

34 Hutchinson WM. Acute optic neuritis and the prognosis of multiple sclerosis. J Neurol Neurosurg Psychiatry 1976;39:283-9.

35 Poeck K, Markus P. Gibt es eine gutartige verlaufoform der multiplen sklerose. Munch Med Wsch 1964; 106:2190-7.

36 Thompson AJ, Hutchinson M, Brazil J, Feighery C, Martin EA. A Clinical and laboratory study of multiple sclerosis. $Q J$ Med 1986;58:69-80. 